\title{
NOVOS REALISMOS NA CONTEMPORANEIDADE: \\ A ESCRITA DE HISTÓRIA
}

\author{
MOURA, Aline de Almeida ${ }^{11}$ \\ "Devemos fazer a história de que o \\ presente tem necessidade" \\ (Le Goff\& Nora, 1988) \\ "Detesto os mortos que voltam. \\ São tão mais nossas as imagens!" \\ (Mário de Andrade, 1924)
}

\section{INTRODUÇÃO:}

"Não tente "começar do começo", pois este livro não tem começo, no sentido em que têm as narrativas e discussões" (GUMBRECHT, 1999, p. 9). É assim que Gumbrecht inicia seu texto Em 1926. Vivendo no limite do tempo (1999), que diferentemente dos outros textos historiográficos, não quer instruir seus leitores ou organizar experiências de realidades passadas. Sua intenção é "fazer pelo menos alguns leitores esquecerem, durante o processo de leitura, que eles não estão vivendo em 1926. Em outras palavras: evocar alguns dos mundos de 1926, re-presentá-los, no sentido de torná-los novamente presentes" (GUMBRECHT, 1999, p. 10).

Sua proposta se insere em um amplo debate sobre o que também poderia ser chamado de escrita realista da realidade: a escrita historiográfica. Como afirma Kramer (2001), a História enquanto disciplina que pretende re-apresentar as realidades passadas, lida com determinadas convenções de escrita e de metodologia, mesmo que essas estejam fragilizadas por pressupostos contemporâneos. As questões sobre o produto final, isto é, a escrita dos resultados obtidos após o levantamento, seleção, análise de fontes, têm sido amplamente discutidas e alternativas de escritas Pontifícia Universidade Católica do estado do Rio de Janeiro (PUC-Rio). 
vêm sendo propostas, enfatizando essa "grafia" da historiografia como parte integrante e relevante também dessa disciplina. Nesse sentido, a escrita historiográfica se liga ao realismo seguindo a proposição de Hamon (1984), que afirma que o foco do realismo está na forma pela qual se faz crer que um texto copia o real através da linguagem. A questão sobre a possibilidade ou não de se atingir proposições verídicas sobre 0 real ${ }^{12}$ é vista como um debate desgastado. No texto de Gumbrecht, a preocupação sobre a forma com que o texto será escrito para que atinja o seu objetivo torna a ideia de realismo conceito chave para se pensar na proposta de uma reconfiguração do trabalho historiográfico.

No presente artigo, pretendo analisar a escrita de Gumbrecht como proposta que foge à convencional escrita narrativa da História como disciplina. Sabendo que sua intenção é enfatizar o aspecto sensual ${ }^{13}$ de re-presentificação do passado, refletindo como essa nova escrita estaria ligada a uma nova função da História na sociedade, enfatizando seu aspecto político assim como o aspecto estético da escrita. Para alcançar tal objetivo, tenho como base as análises do filósofo francês Jacques Rancière sobre a relação entre estética e política, assim como suas posições sobre arte e a História. Como questão tangente, reflito de forma breve a relação entre literatura e História.

12 "Já não se trata, portanto, de responder a uma questão do gênero: como é que a literatura copia a realidade?, questão hoje em dia desinteressante, e sim de considerar o realismo como e fosse uma espécie de speech-act (Austin, Searle) definido por uma postura e uma situação especifica de comunicação, é,assim, responder a uma questão do tipo: como é que a literatura nos faz crer que copia a realidade?, quais são os meios estilísticos que - conscientemente ou não - utiliza para criar este estatuto especial de leitor. (HAMON, 1984, p. 143).

13 "Como um 'ensaio sobre a simultaneidade histórica, meu livro é uma resposta prática à questão de saber até onde um texto pode ir no sentido de proporcionar uma ilusão de uma experiência direta do passado" (GUMBRECHT, 1999, p. 474). 
Ressalto que a preocupação com a escrita do historiador permite o uso de teorias ligadas aos estudos de textos ficcionais literários. Contudo, a História não deve ser tratada como ficção no mesmo sentido da ficção literária, pois embora a escrita tenha papel primordial, a metodologia da operação historiográfica faz com que a relação estabelecida pela escrita seja diferente. A proposta não é ressaltar a dicotomia entre literatura e História, pois esse debate esmaece a reflexão sobre a necessidade de uma revisão das formas de se escrever na disciplina História e sua função no contexto contemporâneo, conforme aponta Rancière ${ }^{14}$. Assim, na primeira sessão será abordada a relação entre escrita de História e realismo. Na parte subsequente serão apresentadas algumas ideias de Rancière e a sua relação com a escrita de História. Em seguida será analisada a proposta de Gumbrecht levando em consideração a definição de regime estético de Rancière. Pretendo, a partir dessas análises, entender a necessidade de se propor novas formas de escrita historiográfica como fez Gumbrecht no livro Em 1926.

\section{A HISTÓRIA COMO REALISMO:}

Ao se pensar na escrita de História, logo poderíamos nos remeter ao acalorado debate sobre a relação entre História e literatura. No meu caso em questão, com minha formação como historiadora, fazia parte do grupo dos que defendem a História como ciência e que por conta disso concebia as ideias de Hayden White -

14 "O real precisa ser ficcionado para ser pensado. Essa posição deve ser distinguida de todo discurso - positivo ou negativo - segundo o qual tudo será "narrativa", com alternância entre "grandes" e "pequenas" narrativas. A noção de "narrativa" nos aprisiona nas oposições de real e do artifício em que se perdem igualmente positivistas e desconstrucionistas. Não se trata de dizer que tudo é ficção. Trata-se de constatar que a ficção da era estética definiu modelos de conexão entre apresentação dos fatos e formas de inteligibilidade que tornam indefinida a fronteira entre razão dos fatos e da ficção, e que esses modos de conexão foram retomados pelos historiadores e analistas da realidade social" (RANCIĖRE, 2005, p. 58). 
um dos teóricos fundamentais para se pensar a escrita na História como, no mínimo, questionáveis. Mas é preciso relativizar. Em seu conhecido texto Meta-história (1992), White propõe, tendo por corpus a produção de alguns historiadores e filósofos da história do século XIX, analisar a História através de seu produto final, da escrita legada pelos historiadores ${ }^{15}$. Para White, a História é um exercício de retórica, sendo essa afirmação facilmente questionada por historiadores como Carlo Ginzburg. A História, para esse pesquisador, trata-se mais do que retórica, trata-se de um esforço metodológico que controla o que será apresentado como dado. Como afirma Ginzburg, a ligação entre história e narrativa vem de indivíduos que não conhecem a prática historiográfica, "criando abismo entre essa prática e a reflexão metodológica" (2002, p. 14). No esforço de ser uma ciência, a História se baseia em todo um aparato metodológico que busca garantir a veracidade e fidedignidade do que está sendo narrado.

De certa forma, a escrita em si só torna uma preocupação nas ultimas décadas, quando o historiador se dá conta que também é um produtor de texto, além de um pesquisador que se baseia em teorias e metodologias de pesquisa. Ou seja, essa certeza cientificista que o historiador tinha a partir de sua metodologia científica vem sendo posta em questão ${ }^{16}$. A escrita passa a ser uma preocupação por definir como as conclusões obtidas a partir da pesquisa serão transmitidas.

A proposição de Rancière sobre a escrita da História é bastante interessante. Ele afirma não estar interessado na questão da

15 "Nessa teoria trato o trabalho histórico como o que ele manifestamente é: uma estrutura verbal na forma de um discurso narrativo em prosa" (WHITE, 1992, p. 11).

16"os historiadores perderam muito de sua ingenuidade e de sua ilusão. Agora sabem que o respeito às regras e às operações próprias à sua disciplina é uma condição necessária, mas não suficiente, para estabelecer a história como um saber específico" (CHARTIER, 2002, p. 17). 
instituição histórica, pois essa tarefa já foi feita por Michel de Certeau ao definir a "operação historiográfica" ${ }^{17}$. Ele enfatiza que "a questão política do conhecimento histórico passa pela análise de uma relação específica: a relação entre o discurso que discute a história e as palavras nas quais ela se escreve" (RANCIÉRE, 2010b, p. 36). E nisso Rancière é mais coerente que White. A questão da operação historiográfica não é omitida no sentido de parecer não haver relevância para o que está sendo escrito, mas é preciso ressaltar que a relação com as palavras também faz parte dessa operação. Rancière reafirma que seu interesse nessa questão se dá pela relação que o discurso histórico passa a ter com o discurso ficcional ${ }^{18}$, nas discussões suscitadas a partir do momento que a "grafia" torna-se importante no fazer historiográfico.

O que proponho é que o discurso histórico está entrelaçado com o modo de pesquisa e a visão de História que o historiador tem. Nesse sentido, se é utilizado o método quantitativo, com a seleção de inúmeras fontes que serão quantificadas e classificadas, a historiografia será mais ligada ao tipo descritivo, com a inserção de inúmeras tabelas, estatísticas e dados que busquem a comprovar determinada hipótese. Se, por outro lado, o historiador busca a análise de um determinado elemento que julgue relevante para relacionar com o contexto de tal elemento, a escrita será mais ligada à narração do modo como é feito na micro-história. Assim, o modo como o texto é escrita está intimamente ligado ao modo como o

17 "um discurso de poder sobre o qual Michel de Certeau disse tudo o que havia de interessante para dizer" (RANCIÈRE, 2010b, p. 35). Michel de Certeau, no capítulo "A operação historiográfica", discute, a produção da história como resultado de um processo de pesquisa, análise e escrita. A sua questão é pensar em "O que fabrica o historiador quando 'faz história'" (cf.: CERTEAU, 1988).

18 "O que me interessa é a relação entre essa apreensão do ser falante e a questão das fronteiras entre os modos do discurso: o que significa quando dizemos que determinado discurso provem da ciência, e não à literatura, ou o contrário?" (RANCIÈRE, 2010b, p. 35). 
historiador lida com as fontes, a sua visão de História. A partir daí que se dá a escrita, e não o contrário, o modo de escrita não é a parte racionalizada anteriormente no trabalho do historiador, como propôs White.

Entender a História como um discurso realista se deve à ideia de que 1) o discurso tem extrema relevância para a operação historiográfica; 2) o realismo é concebido em um sentido amplo de relação que determinado discurso tem com os fatos e, no caso da História, por mais que haja discussões sobre métodos de pesquisa, sobre a possibilidade ou não de se atingir proposições verídicas sobre a realidade, o fato é que as fontes tem o "poder de veto". Não é possível afirmar qualquer coisa sobre qualquer período.

Rancière afirma que o modo de fazer História que se pauta apenas na busca por fontes e dados está condenada a um empirismo, "renunciando questionar os modos de escrita que dão às palavras da história e às palavras do historiador a aparência de uma verdade" (RANCIÉRE, 2010b, p. 37). Fica-se preso tal como Funes, o memorioso no conto de Jorge L. Borges, sem capacidade de abstração. É preciso ter consciência que a História enquanto ciência transmite suas pesquisas por meia da linguagem escrita, fazendo que ela também seja parte do trabalho historiográfico. Para Rancière, a representação "não é o acto de produzir uma forma visível, é sim o acto de dar um equivalente (...) É a voz de um corpo que transforma um acontecimento sensível num outro, esforçando-se por nos fazer "ver" o que esse corpo viu, por nos fazer ver o que ele nos diz" (RANCIÈRE, 2010c, p. 139). Nesse trecho, o autor trata da relação entre palavra e fotografia, como ambas são figuras que substituem o sensível. E é nesse sentido que a escrita de História deve ser entendida, como uma construção de imagens que nos possibilita dar voz aos mortos através de pesquisa e metodologia sim, mas também através das imagens evocadas pelas palavras. 


\section{A PARTILHA DO SENSÍVEL E A ESCRITA DE HISTÓRIA}

Jacques Rancière propõe em A partilha do sensível (2005) a existência de três regimes de identificação da arte, tendo por base a relação entre referência e signo - a saber, o regime ético, o regime representativo e o regime estético. Para o autor, essa "partilha do sensível" se relaciona com a possibilidade de se tomar parte da palavra comum, havendo um aspecto político dentro da estética, uma vez que está ligada às formas definidas a priori para se expressar, e quem pode se expressar dentro dessas formas. No regime ético, a arte se encontra identificada com as imagens, questionadas sobre 0 ponto de vista de sua origem ( $e$, consequentemente, seu teor de verdade) e o seu destino. Nesse regime, seguindo as proposições de Platão, "a arte não existe, apenas existem artes, maneiras de fazer" (RANCIÈRE, 2005, p. 28). É o objeto que determina o tipo de expressão. O segundo regime é o poético ou representativo, em que a arte se identifica como par poiesis/ mimesis, pois são esses conceitos que organizam a maneira de fazer, ver e julgar a visibilidade das artes (cf.: RANCIÈRE, 2005, p. 31). Esse regime se pauta por mostrar modelos de narratividade, hierarquizando as formas de se partilhar o sensível, tendo por base as proposições de Aristóteles. Já o regime estético não está mais ligado às formas de fazer, "mas pela distinção de um modo de ser sensível próprio aos produtos de arte" (RANCIÈRE, 2005, p. 32). Assim, a arte faz parte de um tipo específico de partilha do sensível. Nesse regime não há mais o domínio da noção mimética na arte, em que predomina a necessidade de representação da realidade. Pode-se afirmar, nessa conjuntura, que essa noção de representação não deve mais ser entendida como categoria chave para se compreender a produção artística contemporânea, fundando uma autonomia das artes e a 
identificação da arte com a vida em si mesma ${ }^{19}$. Esse regime estaria ligado a uma democratização dentro dessa partilha do sensível ao implodir as regras e hierarquizações do regime representativo.

Rancière também trata de uma interessante discussão sobre os modos de se escrever na ficção "modernista", propondo um novo olhar para questões que pareciam básicas e inquestionáveis. Por exemplo, é clássico o texto de Roland Barthes, "O efeito de realidade", no qual ele argumenta que a descrição presente na obra realista, embora pareça desnecessária, tem por utilidade transmitir um efeito de real para o texto literário. Rancière (2010) argumenta que na verdade essas descrições têm por sentido não dar realidade à obra, mas sim dar vida ${ }^{20}$. Assim, a descrição existente, em vez de "parar" a ação da narrativa, a enche de vida, pois é isso que se faz cotidianamente, observa-se ao redor. E esse "cotidiano ocioso" de apreciação da vida presente na descrição pode fazer parte da narrativa através dessa nova distribuição do sensível ${ }^{21}$.

As proposições de Rancière têm interessante relevância para se pensar sobre a alternativa de escrita de Gumbrecht, entendida como já inserida no que é o regime estético da arte. Sobre a escolha estilística, no texto de Gumbrecht há, conscientemente, uma predominância do aspecto descritivo, com claro intuito de se presentificar o passado, dando mais vida ao que está sendo narrado. Assim, tanto Rancière por sua exposição teórica, quanto Gumbrecht,

19 "Funda a uma só vez, a autonomia da arte e a identificação de suas formas com as formas pelas quais a vida se forma a si mesma" (RANCIÈRE, 2005, p. 34).

20"O barômetro não está lá para comprovar que o real é o real. A questão não é o real, é a vida, é o momento quando a 'vida nua' - a vida normalmente devotada a olhar, dia após dia, se o tempo será bom ou ruim - assume a temporalidade de uma cadeia de eventos sensorialmente apreciáveis para serem relatados. O ocioso barômetro expressa uma poética da vida ainda desconhecida (...)" (RANCIÉRE, 2010, p.79).

21 Para mais explicitações sobre o argumento de Rancière, consultar o texto "O efeito de realidade e a política da ficção" (2010). 
pela forma escolhida para escrever sua História, tratam da forma descritiva com essa mesma função.

Gumbrecht ressalta ainda que seja uma pretensão acreditar que escrever História significa "fazer História", uma vez que na escrita dessa disciplina as fontes têm "direito ao veto". Logo, não se pode afirmar qualquer coisa sob a pena de ser acusado de falsificação. Para ele, a questão é como tornar a História real, como fundir escrita historiográfica com a vida que fora vivida para causar o efeito de re-presentificação. Rancière assevera que "os enunciados literários ou políticos fazem efeito no real" (RANCIÈRE, 2005, p. 59), afirmação que corresponde à proposição de Gumbrecht. E pensando em um momento de crise, como é descrito por Rancière, em que o terreno estético tem posição fundamental para se pensar na democratização e na relação com os referentes ${ }^{22}$, a proposta de Gumbrecht se torna uma alternativa no mínimo coerente no atual estado de debate e reconfiguração da arte e da História.

Em suma, pensando na variação dos regimes de arte, como proposto por Rancière, assim como as mudanças de perspectiva sobra a escrita modernista, percebe-se que o trabalho de Gumbrecht se insere nesse campo de reconfiguração e questionamento dos pressupostos da historiográfica através da proposta de uma alternativa para a História, para que a disciplina tenha um novo valor e função dentro desse contexto de questionamentos. Conforme o autor afirma, a tese "de que "se pode aprender com a História" perdeu o seu poder de persuasão" (GUMBRECHT, 1999, p. 460), as escritas de História até então canonizadas devem sim ser questionadas para que consiga corresponder às necessidades contemporâneas.

22 "A multiplicação dos discursos denunciando a crise da arte ou sua captação fatal pelo discurso, a generalização do espetáculo ou a morte da imagem são indicações de que, hoje em dia, é no terreno estético que prossegue uma batalha ontem centrada nas promessas da emancipação e nas ilusões e desilusões da história" (RANCIÈRE, 2005, p. 11-12). 


\section{GUMBRECHT E O REGIME ESTÉTICO}

Rancière $(2005 b)$ propõe o entrelaçamento entre política e estética ${ }^{23}$, segundo o qual há uma dimensão estética na experiência política, hipótese já presente em sua tese de doutorado La Nuit des prolétaire. Nesse trabalho, "showed that the core of the emancipation of the workers was an aesthetic revolution" (RANCIÈRE, 2005b, p. 14), ou seja, demonstra que as mudanças ocorridas no século XIX também são mudanças de valores poéticos e de partição da esfera da experiência. A segunda forma de ligação entre as revoluções políticas e estéticas está na discussão sobre escrita de História, quando os historiadores da História das mentalidades passam a dar voz àqueles que eram esquecidos em sua escrita, passando a não se preocupar apenas com os grandes personagens, mas também com as pessoas comuns, que podem se apropriar da linguagem. Essa apropriação teve consequências na metodologia das ciências sociais - que se postulava como escrita desmistificadora das ilusões presentes na literatura. Assim, as ciências sociais também fazem parte dessa revolução estética de tomada da escrita, de possibilidade de se partilhar o sensível. Rancière ainda define a literariedade como: "the power that tears bodies away from their natural destination" (RANCIÈRE, 2005b, p. 16). Nessa proposta de entrelaçamento entre política e estético, a alternativa de escrita de faz parte de uma tentativa de se conceber a História como fazendo parte tanto de um questionamento estético quanto político, no sentido de ter efeito nas sociedades.

Logo, acredito que é profícuo pensar a proposta de Gumbrecht sobre a História e sua função na contemporaneidade levando em consideração a reconfiguração na arte tal como é proposto por

23 Rancière analisa estética no sentido kantiano, de formas de sensibilidade, como matéria de tempo e espaço e não na sua ligação pura e simples com a arte (RANCIÈRE, 2005b, p. 13). 
Rancière. Se a arte muda a sua perspectiva e busca uma relação mais viva com o real, a disciplina História também deve refletir sobre novos métodos e escritas passíveis de dar mais vida a sua produção. Essa disciplina ao ficar restrita ao seu caráter científico acabou por simplificar as realidades passadas. Além disso, em um contexto em que, como afirma Gumbrecht, a História já não tem mais aquela tarefa pedagógica, entender a História e sua reconfiguração no contexto contemporâneo exigem novas formas de a disciplina se relacionar coma produção do conhecimento das realidades passadas.

Rancière se refere, a partir da sua análise dos regimes, pensar sobre conceitos como modernidade, pós-modernidade e vanguarda. Sobre a modernidade, ele afirma que opera um recorte equívoco no regime estético da arte, fazendo com que haja um sentido único de temporalidade em um período que é heterogêneo ${ }^{24}$. Perspectiva interessante, pois a proposta de Gumbrecht se insere na sua proposta de simultaneidade do tempo, ou seja, essa heterogeneidade de que Rancière trata. Gumbrecht acredita que a relação temporal vem mudando através de uma expansão do presente, tornando necessária essa experiência direta do passado.

De qualquer forma, Rancière afirma que o "regime estético de arte que faz da arte uma forma autônoma de vida" (RANCIÈRE, 2005, p. 37) e é essa a sugestão de Gumbrecht. Uma vez que "o modelo teleológico da modernidade tornou-se insustentável" (RANCIÈRE, 2005, p. 47), a História, tal como vista por Gumbrecht, tem que levar os seus leitores a experimentar outras vivências a partir de seus textos. É interessante que, para Gumbrecht, é o fato de ser um texto historiográfico que vai fazer com que essa vivência seja mais bem

24 "A ideia de modernidade é uma noção equivoca que gostaria de produzir um corte na configuração complexa do regime estético das artes, reter as formas de ruptura, os gestos iconoclastas etc, separando-os do contexto que os autoriza: a reprodução generalizada, a interpretação, a história, o museu, o patrimônio... Ela gostaria que houvesse um sentido único, quando a temporalidade própria do regime estético das artes é o da co-presença de temporalidades heterogêneas" (2005, p. 37). 
sentida ${ }^{25}$. Subvertendo a proposta de Aristóteles sobre a superioridade da ficção sobre a História ${ }^{26}$. Seu intuito não é organizar o caos que a realidade apresenta, ou interpretá-la. Com a nova função para a História conforme postulado por Gumbrecht, essa hierarquização é irrelevante, por mais que o trabalho historiográfico tenha um sentido de alcançar o seu objetivo de presentificação. E o trabalho se torna historiográfico porque houve uma pesquisa anterior a elaboração do livro, sendo que tal pesquisa é que definiu o que pode ou não ser dito sobre o que ocorreu e o que se vivenciou em 1926.

Gumbrecht propõe essa nova escrita por acreditar em uma nova função da História: satisfazer a necessidade de se viajar para o passado (cf.: GUMBRECHT, 1999). Para isso, fora necessária desenvolver essa diversa forma de escrita, mais ligado ao descrever as realidades passadas. Em seu texto, há51 verbetes que descrevem a vivência em 1926, sendo que a parte metodológica é escrita apenas no final do livro, com a explicitação das fontes, seleções e pressupostos utilizados da elaboração de seu texto. Por exemplo, no verbete "Jazz", ele descreve através de verbos no presente, falando do agora como se fosse 1926 , das sensações que esse novo ritmo suscitou no ano de 1926. São usados como referência que comprovam as suas afirmações outros verbetes, fazendo com que essa comprovação seja o mergulho cada vez maior nesse ano. Faz-

25"Embora o autor tenha inventado uma forma textual especifica para cada verbete,sucesso deste livro como um todo depende da afirmação de que ele não foi "inventado" (isto é, da afirmação de que o seu conteúdo é totalmente referencial). O efeito de evocar o passado se baseia nessa implicação mais ou menos "ontológica". Um romance histórico (se o autor fosse capaz de escrever ficção) não teria o mesmo trabalho" (GUMBRECHT, 1999, p. 10).

26 "A soberania da literatura [sobre a história em Aristóteles] não é, portanto, o reino da ficção. É, ao contrario, um regime de indistinção entre a razão das ordenações descritivas e narrativas da ficção e as ordenações da descrição e interpretação dos fenômenos do mundo histórico e social" (RANCIÈRE, 2005, p. 55). 
se, com isso, uma leitura fragmentada, que não precisa necessariamente a ordem de início, meio e fim, sendo que olhar cada aspecto desse ano leva o leitor para outros aspectos desse mesmo período.

Percebe-se que no texto em si não há uma explicitação das fontes usadas para propor tais afirmações sobre o ano de 1926. Caso o leitor não leia a parte final - que Gumbrecht explicita como leitura dispensável - não saberá quais as fontes, os critérios de seleção, os métodos empregados para a escrita desse livro. O olhar do historiador, que já é treinado muitas vezes a procurar esses elementos do empírico que comprovam o que este sendo afirmado, surpreende-se com essa proposta de Gumbrecht. Parece, no primeiro momento, que ele tirou essas afirmações da cabeça, que sonhou que estava em 1926 e escreveu. Contudo, o autor garante e demonstra de sua maneira (na parte final do livro) que houve uma pesquisa e que é essa pesquisa que garantiria o sucesso de seu objetivo de representificação.

Em suma, insere-se a escrita de Gumbrecht nesse contexto de ruína da representação como conceito chave até mesmo para se pensar a História. Tanto que seu intuito não é representar, no sentido de mimetizar pura e simplesmente as realidades. O autor, a partir de seu texto que se tornar novamente presente, se possível, as vivências de 1926. Mais uma vez, seu projeto se insere nessa reconfiguração das artes proposta por Rancière ${ }^{27}$. Faz-se necessária essa reconfiguração para que a História faça sentido nos estudos atuais e não garanta sua importância pela sua tradicionalidade no pensamento ocidental.

27 "O regime estético da arte é, antes de tudo, a ruína do sistema de representação, isto é, de um sistema em que a dignidade dos temas comandava a hierarquia dos gêneros de representação" (RANCIÈRE, 2005, p. 47). 


\section{CONCLUSÃO:}

Gumbrecht, diferentemente do discurso cientificista da História, não faz referência em seu texto aos arquivos consultados, aproximando-se de uma escrita realista sobre as realidades passadas $^{28}$. A sua forma de escrita se deve a sua perspectiva de que a História tem uma nova função dentro da sociedade frente às mudanças ocorridas e aos longos questionamentos. Procurei ressaltar nesse trabalho a profícua relação que pode ser estabelecida entre as proposições de Rancière e a alternativa historiográfica de Gumbrecht. Acredito que a História deve sim ter mais vida, e a preocupação cientificista da História acabou por encobrir esse aspecto, simplificando as vivências das realidades passadas. Mais uma vez, não se trata de igualar a História à literatura, pois esse debate não é o foco. Mas pensar sobre a História enquanto uma escrita que possui efeitos sobre o real, assim como a literatura, mas esse efeito é diverso e alcançado a partir de outras estratégias de leitura. Gumbrecht afirma que Em 1926 o efeito de presença se dará de forma mais adequada por ser um trabalho historiográfico. E por trabalho historiográfico subentende-se a pesquisa pela qual Gumbrecht submeteu a sua escrita, assim como a estrutura de escrita em si escolhida para se legar as conclusões de sua pesquisa. A escrita faz parte desse trabalho do historiador. A escrita que deve ser revista no regime estético das artes, sem ficar restringido apenas à velha forma representacional que já nem faz tanto sentido nos debates contemporâneos.

28 "Contrariamente ao discurso cientifico, que muitas vezes coloca, em notas de pé de página, em bibliografia no fim do volume, em citações explicitas, referencias destinadas a autenticar o seu dizer, o texto realista integra-as no seu próprio corpo sob a forma de cenários e de personagenstipo" (HAMON, 153). 
Minha preocupação não foi saber se Gumbrecht alcança ou não o seu objetivo de re-presentificação dos mundos de 1926, mas refletir, a partir das referências de Rancière sobre a escrita de História, tal como proposta por esse teórico. Trata-se de um exercício estimulante e que supera a discussão que é quase "chover no molhado" entre literatura e História. É necessário um sopro de vida na História e se não é possível mais aprender com a História, que os historiadores não se fechem em suas fontes primárias e que se arrisquem. Não para serem todos literatos, mas para refletir sobre a real função de sua disciplina.

\section{REFERÊNCIAS:}

CHARTIER, Roger. A beira da falésia. A história entre certezas e inquietudes. Porto Alegre: Editora Universidade/ UFRGS, 2002.

GINZBURG, Carlo. Relações de força. História, retórica, prova. São Paulo: Companhia das Letras, 2002.

GUMBRECHT, Hans Ulrich. Em 1926. Vivendo no limite do tempo. Rio de Janeiro: Record, 1999.

. Produção de presença: o que o sentido não consegue transmitir. Rio de Janeiro: Contraponto, Editora PUC-Rio, 2010.

HAMON, Philippe. "Um discurso determinado". In: BARTHES, Roland. Literatura e realidade. Lisboa: Dom Quixote, 1984, p. 129-193.

KRAMER, Lloyd S. "Literatura, crítica e imaginação histórica: o desafio literário de Hayden White e Dominick La Capra". In: HUNT, Lynn. A nova história cultural. São Paulo: Martins Fontes, 2001, p. 131173.

RANCIÉRE, Jacques. A partilha do sensível. São Paulo: EXO experimental, 2005.

. "From politics to aesthetics?". In: Paragraph. Vol. 28. N. 1. Março de 2005b, p. 13-25.

. "O efeito de realidade e a política da ficção". In: Novos estudos. Número 86, março de 2010, p. 75-90.

."A poética do saber: sobre os nomes da história" In:

Urdimento - Revista de Estudos em Artes Cênicas/Universidade 
do Estado de Santa Catarina. Programa de Pós-Graduação em Teatro. Florianópolis: UDESC/CEART.Vol1, n.15,Out 2010b, p. 33-43. . "A imagem intolerável". In: O espectador emancipado. Trad. José Miranda Justo. Lisboa: Orfeu Negro, 2010c, p. 123-153.

WHITE, Hayden. Meta-história: a imaginação histórica do século XIX. São Paulo: Editora da Universidade de São Paulo, 1992. 